\title{
Concepções de professoras-mães sobre o bullying e a educação inclusiva
}

Anna Karolina Santoro Borges ${ }^{1}$ Carlos Henrique Ferreira da Silva ${ }^{2}$ Letícia Lovato Dellazzana-Zanon ${ }^{3}$

\begin{abstract}
Resumo:
A partir da perspectiva da Psicologia do Desenvolvimento, o objetivo deste estudo foi investigar a concepção das mães de filhos com deficiência, que são também professoras, sobre bullying relacionado à criança com deficiência. Participaram do estudo quatro professoras de ensino fundamental I da rede pública, duas delas também mães de pessoas com deficiência. Utilizaram-se os instrumentos: Questionário sobre formação e trabalho das professoras; Entrevista semiestruturada sobre bullying e inclusão; e Questionário sobre bullying direcionado aos professores de alunos com deficiência. Os dados foram analisados por meio da análise de conteúdo. Os resultados revelaram: falta de preparo de professores para trabalhar com questões relativas à inclusão e ao bullying, falta de infraestrutura da escola para bem receber alunos com deficiência, medo em relação ao futuro e à inclusão dos filhos das professoras mães de pessoas com deficiência na sociedade e esforço para que a inclusão, de fato, ocorra com seus alunos. Constatou-se que as professoras-mães manifestaram sentimento de tristeza e angústia, pois ao responderem sobre a educação inclusiva não puderam deixar de relatar suas experiências como mães de crianças com deficiência.
\end{abstract}

\section{Palavras-chave:}

Educação inclusiva. Aluno com deficiências. Bullying. Maternidade.

\section{"Mother-teachers" conceptions about bullying and inclusive education}

\footnotetext{
Abstract:

From the perspective of Developmental Psychology, this study aimed to investigate the conception of mothers of children with disabilities who are also teachers about bullying related to children with

1 Pedagoga, Mestre em Psicologia pela PUC-Campinas, Doutoranda em Psicologia, Bolsista da Coordenação de Aperfeiçoamento de Pessoal de Nível Superior (CAPES), Pontifícia Universidade Católica de Campinas. E-mail: annakarolinapedagoga@gmail. com. ORCID iD: http://orcid.org/0000-0003-2619-5291.

2 Psicólogo, Mestrando em Psicologia, Bolsista do Conselho Nacional de Desenvolvimento Científico e Tecnológico (CNPq), Pontifícia Universidade Católica de Campinas. E-mail: carloshfdasilva@outlook.com. ORCID iD: http://orcid.org/0000-0001-8025-8930. 3 Psicóloga, Doutora em Psicologia pela Universidade Federal do Rio Grande do Sul, Pontifícia Universidade Católica de Campinas. E-mail: leticiadellazzana@gmail.com. ORCID iD: http://orcid.org/0000-0003-0649-1675.
} 
disabilities. Four public elementary school teachers participated in the study, two of them also mothers of people with disabilities. The following instruments were used: Teacher Education and Work Questionnaire, Semi-structured Interview on Bullying and Inclusion and Bullying Questionnaire Directed at Teachers of Students with Disabilities. Data were generated through content analysis. The results revealed: unpreparedness of teachers to work with issues related to inclusion and bullying, lack of school infrastructure to accommodate students with disabilities, fear of the future and the inclusion of children of teachers who are mothers of people with disabilities in society and the effort for inclusion, in fact, occur with its students. It was found that the mother-teachers expressed feelings of sadness and anguish because when they answered about Inclusive Education, they could not fail to report their experiences as mothers of children with disabilities.

\section{Keywords:}

Inclusive education. Student with disabilities. Bullying. Maternity.

\section{Las concepciones de las madres-maestras sobre el acoso escolar y la educación inclusiva}

\section{Resumen:}

Desde la perspectiva de la Psicología del Desarrollo, el objetivo de este estudio fue investigar la concepción de las madres de niños con discapacidad, que también son docentes, sobre el acoso escolar relacionado con los niños con discapacidad. En el estudio participaron cuatro maestras de escuelas primarias públicas, dos de ellas también madres de personas con discapacidad. Se utilizaron los siguientes instrumentos: Cuestionario de Formación y Trabajo Docente, Entrevista Semiestructurada sobre Bullying e Inclusión y Cuestionario de Bullying Dirigido a Docentes de Alumnos con Discapacidad. Los datos se analizaron mediante análisis de contenido. Los resultados revelaron: falta de preparación de los docentes para trabajar con temas relacionados con la inclusión y el acoso escolar, falta de infraestructura escolar para acoger a estudiantes con discapacidad, miedo al futuro y la inclusión de los hijos de docentes que son madres de personas con discapacidad en la sociedad y esfuerzo para que la inclusión, de hecho, se produzca con sus alumnos. Se encontró que las maestras-madres expresaron sentimientos de tristeza y angustia, pues al responder sobre Educación Integrada no pudieron dejar de relatar sus vivencias como madres de niños con discapacidad.

Palabras clave:

Educación inclusiva. Estudiante con discapacidad. Acoso escolar. Maternidad.

\section{Introdução}

O impacto de ter um filho(a) com deficiência, congênita ou adquirida, pode significar mudanças de rotina, de estilo de vida e gerar sentimentos semelhantes a um processo de luto, que podem resultar na dificuldade em manter amizades, relações de lazer e uma qualidade de vida saudável (PALACIOS, 2004). Pode haver necessidade de os pais se adaptarem em um processo longo e dolorido de ressignificação de sonhos e de projetos (PANIAGUA, 2003), pois o(a) filho(a) idealizado(a) dá lugar ao filho(a) real, que precisará de uma identidade em que se respeite seus limites e lhe lancem novas perspectivas (BOSSI; ARDANS-BONIFACINO, 2016). O cuidado, diante das necessidades do(a) filho(a) com deficiência pode ser árduo, uma vez que todas as tarefas de cuidado precisam considerar suas limitações e impossibilidades, o que pode trazer consequências emocionais momentâneas ou durarem a vida inteira (OLIVEIRA; POLETTO, 2015). 
Este artigo está fundamentado na Psicologia do Desenvolvimento, a partir da perspectiva desenvolvimentista de Sameroff (2010), que em sua teoria unificada do desenvolvimento propõe a integração de estudos interdisciplinares e leva em consideração as possíveis relações das experiências do indivíduo e de seus contextos. Muitas situações vivenciadas pelas participantes, professoras-mães, podem indicar vivências de tantas outras pessoas em situação semelhante ou mesmo no papel de uma ou outra função (mãe ou professora), que estejam em um contexto ou em um meio semelhante ou comum. O levantamento das concepções de professoras-mães sobre o bullying e a educação inclusiva pode elucidar situações que podem ser trabalhadas de modo coletivo nas escolas, levando a melhorias para todos os atores envolvidos.

Segundo Castro e Piccinini (2004), as vivências de pais e de mães podem ser semelhantes. No entanto, os autores afirmam que as mães tendem a se envolver mais nos processos de reabilitação dos filhos, possivelmente, pela característica sociocultural da mulher assumir o cuidado da família. Em função disso, essas mulheres podem estabelecer relações de codependência com os filhos, deixando a vida conjugal em último plano (CASTRO; PICCININI, 2004; PEGORARO; SMEHA, 2013). Os progenitores podem superproteger o(a) filho(a) com deficiência e oferecer mais cuidados do que necessário na tentativa de reparação de danos. Isso suprime a autonomia e gera uma relação de dependência mútua entre pais e filhos. Por outro lado, os progenitores podem manifestar preocupação com a dependência funcional, a educação e o trabalho de seu(sua) filho(a) com deficiência (PEGORARO; SMEHA, 2013). A sensação de fragilidade e a percepção da própria finitude tende a gerar a incerteza nos pais, transparecendo o temor de deixar o(a) filho(a) vulnerável, ao saberem que o(a) filho(a) não é capaz realizar ações necessárias à sua sobrevivência (BOWLBY, 1989).

Uma das preocupações dos pais de crianças com deficiência é o bullying. O bullying diz respeito a uma forma de violência caracterizada pela intencionalidade, pelo caráter repetitivo e pelo desequilíbrio de poder entre agressores e vítimas (BREIVIK; OLWEUS, 2015). Considerado um dos principais problemas para o desenvolvimento e a saúde de crianças e adolescentes que frequentam a escola, o bullying não tem poupado os alunos com deficiência. As limitações físicas ou intelectuais das crianças com deficiência podem dificultar suas relações interpessoais, prejudicando o desenvolvimento de suas habilidades sociais (MAMAS et al., 2020), gerando um baixo status social e rejeição (BROOMHEAD, 2019). Assim, o preconceito, a dificuldade dos outros estudantes em aceitar as diferenças e a rejeição podem contribuir para que ocorram situações de bullying (LOPES NETO, 2005; OLIVEIRA et al., 2018).

Quanto à detecção do bullying, tanto pais como professores tendem a tomar conhecimento de que o bullying está ocorrendo quando os efeitos causados nos alvos se tornam muito evidentes (SUDERMANN; JAFFE; SCHIECK, 1996). A falta de intervenção da equipe escolar em relação ao fenômeno pode ser interpretada como um reforço para o comportamento do autor de bullying, o que colabora para a manutenção do fenômeno (BORGES; DELLAZZANA-ZANON, 2019; DELLAZZANA-ZANON; SATTLER; FREITAS, 2010).

Evidências sugerem que as crianças com deficiência podem enfrentar o bullying com mais frequência do que as sem deficiência (SINGH; CHOPRA, 2019). Sabe-se também que alunos com deficiência podem exibir maiores índices de comportamento agressivo e desafiador e, por esse motivo, estarem mais envolvidos no fenômeno (ROSE; MONDA-AMAYA; ESPELAGE, 2011; UNNEVER; CORNELL, 2003). Isso pode ocorrer quando os alunos com deficiência apresentam uma dificuldade em construir relações de amizade com seus pares, seja por dificuldades de comunicação, por falta de habilidades sociais ou mesmo por questões cognitivas (ALLEN et al., 2021). Embora possa parecer o contrário, não são as crianças com deficiências severas que mais sofrem o bullying. Evidências indicam que o fenômeno é mais frequente em crianças com deficiências leves ou moderadas, uma vez que as provocações dos agressores são ignoradas pelas crianças com deficiências mais severas, que não se percebem como alvos de provocações (MOONEY; SMITH, 1995). 
A legislação brasileira, sobretudo a Lei Brasileira de Inclusão da Pessoa com Deficiência (LBI) (BRASIL, 2015b), preconiza uma escola que inclua a todos e perceba as diferenças entre as pessoas como positivas. Entretanto, na prática, ainda há um longo caminho a ser percorrido para que isso se torne realidade. Um dos aspectos centrais para que a inclusão ocorra de fato é a formação de professores (SANTOS; MOLON, 2016). No entanto, sabe-se que é necessário que haja uma infraestrutura que sustente o sistema inclusivo, que não tem sido oferecida aos professores na maioria das escolas brasileiras (ALVES; XAVIER; PAULA, 2019; BORGES; DELLAZZANA-ZANON, 2019).

A inclusão de alunos com deficiência, no sistema regular de ensino, tem ocorrido muito mais pelo comprometimento dos professores do que pelas condições materiais e de capital humano disponibilizadas pelo governo (BORGES; DELLAZZANA-ZANON, 2019). Contudo, os pais de alunos com deficiência comumente fazem cobranças quanto à capacidade, à formação e à competência dos professores de educação básica para trabalhar com as crianças com deficiência (SMEHA; OLIVEIRA, 2014; SILVA; MARTINS, 2017). Porém, podem faltar-lhes o conhecimento da realidade escolar e dos problemas cotidianos, com que os professores precisam lidar. Considerando essas questões, $o$ objetivo deste estudo foi investigar a concepção de mães de filhos com deficiência, que são também professoras, sobre bullying relacionado à criança com deficiência no ensino fundamental I.

\section{Método}

\section{Participantes}

Participaram do estudo quatro professoras, titulares da rede municipal de educação de uma cidade do interior de São Paulo, que atuam no ensino fundamental I, sendo duas participantes mães de pessoas com deficiências, Amanda ${ }^{4}$, com uma filha de dezenove anos, e Fabiana, com um filho de quatro anos, e duas não mães de pessoas com deficiência, Beatriz e Cecília. Os critérios de inclusão foram: ser professora efetiva do ensino fundamental I da rede municipal de uma cidade do interior de São Paulo e ter um(a) aluno(a) com deficiência na sua sala ou ter tido um(a) aluno(a) com deficiência no último ano. O critério de exclusão foi desistir do estudo em algum momento de seu curso.

Quadro 1: Caracterização das participantes

\begin{tabular}{|l|c|c|c|c|c|c|c|}
\hline Participante & $\begin{array}{c}\text { Idade } \\
\text { (anos) }\end{array}$ & $\begin{array}{c}\text { Mãe de } \\
\text { PCD }\end{array}$ & $\begin{array}{c}\text { Ensino } \\
\text { Superior em } \\
\text { Pedagogia }\end{array}$ & $\begin{array}{c}\text { Ensino } \\
\text { Superior em } \\
\text { outro curso }\end{array}$ & $\begin{array}{c}\text { PG lato } \\
\text { sensu }\end{array}$ & $\begin{array}{c}\text { Docência no } \\
\text { EFI } \\
\text { (anos) }\end{array}$ & $\begin{array}{c}\text { No de } \\
\text { alunos por } \\
\text { turma }\end{array}$ \\
\hline Amanda & 54 & $\mathrm{x}$ & & $\mathrm{x}$ & & 17 & 30 \\
\hline Cecília & 40 & & & $\mathrm{x}$ & $\mathrm{x}$ & 18 & 30 \\
\hline Beatriz & 37 & & $\mathrm{x}$ & & $\mathrm{x}$ & 10 & 28 \\
\hline Fabiana & 33 & $\mathrm{x}$ & $\mathrm{x}$ & & $\mathrm{x}$ & 13 & 27 \\
\hline
\end{tabular}

Notas: PCD: pessoa com deficiência. PG: Pós-Graduação. EFI: Ensino Fundamental I. Fonte: Elaborado pelos autores. 


\section{Instrumentos}

Foram utilizados três instrumentos no estudo. O Questionário sobre formação e trabalho das professoras (LABORATÓRIO DE PSICOLOGIA E EPISTEMOLOGIA GENÉTICA [LAPEGE/ UFRGS], 2010a), cujo objetivo foi obter a caracterização da participante e os dados sobre sua formação profissional. A "Entrevista semiestruturada sobre bullying e inclusão", inspirada na entrevista do LAPEGE/UFRGS (2010b), que teve como foco investigar os seguintes temas: 1) o que professoras de ensino fundamental I pensam sobre o fenômeno bullying e sobre a inclusão escolar de crianças com deficiência; 2) quais as definições dessas professoras para o bullying e para a escola inclusiva; 3) qual a finalidade, para as professoras, de se trabalhar com formas de evitar e intervir em situações de bullying; 4) que estratégias as professoras utilizam para a promoção da inclusão escolar; 5) como julgam que a professora deveria agir em duas situações (mini-histórias) que envolvem crianças com deficiência e bullying. E, por fim, o "Questionário sobre bullying direcionado aos professores de alunos com deficiência", cujo objetivo foi investigar as concepções de professores sobre seu aluno com deficiência e sobre sua convivência com os seus colegas.

\section{Procedimentos gerais}

As professoras que aceitaram participar da pesquisa foram contatadas individualmente e assinaram o "Termo de Consentimento Livre e Esclarecido" (TCLE). Combinou-se o dia e o horário mais conveniente para as entrevistas, que foram realizadas individualmente, gravadas em áudio e, posteriormente, transcritas. O tempo médio das entrevistas foi de cinquenta minutos. O projeto de pesquisa foi aprovado pelo Comitê de Ética em Pesquisa da Pontifícia Universidade Católica de Campinas (CAAE 66606417.5.0000.5481).

As entrevistas foram analisadas por meio de análise de conteúdo (LAVILLE; DIONNE, 1999). Realizou-se uma análise de conteúdo do tipo aberta, em que as categorias apareceram de acordo com as respostas dos participantes, após uma leitura exaustiva, e tomaram forma ao longo da própria análise, por meio da organização dos elementos por parentesco de sentido. A escolha do modelo aberto se deu pelo fato das temáticas bullying e inclusão serem ainda pouco pesquisadas no Brasil.

\section{Resultados e discussão}

Após a leitura exaustiva das entrevistas, os dados semelhantes foram organizados por parentesco de sentido em três categorias: 1) Bullying; 2) educação inclusiva; 3) relação entre o bullying e a educação inclusiva. Na primeira categoria, foram incluídas as concepções referentes ao bullying. $\mathrm{Na}$ segunda categoria, foram colocadas todas as concepções sobre a inclusão das crianças com deficiência na rede regular de ensino. Por fim, na terceira categoria, foram incluídas as concepções das participantes sobre as duas temáticas em conjunto. O quadro dois apresenta as categorias e suas subcategorias. 
Quadro 2: Categorias e subcategorias da análise de conteúdo

\begin{tabular}{|c|c|}
\hline Categoria & Subcategoria \\
\hline \multirow{2}{*}{ Bullying } & Definição de Bullying \\
\cline { 2 - 2 } & Ocorrência de Bullying na Escola \\
\cline { 2 - 2 } & Estratégias de Ação \\
\hline \multirow{2}{*}{ Educação Inclusiva } & Definição de Educação Inclusiva \\
\cline { 2 - 2 } & Finalidades da Educação Inclusiva \\
\cline { 2 - 2 } & Educação Inclusiva Centrada no Filho \\
\hline Relação entre o Bullying e a Educação Inclusiva & - \\
\hline
\end{tabular}

Fonte: Elaborado pelos autores

A seguir são apresentados os resultados de acordo com as categorias descritas.

\section{Bullying}

No que se refere à primeira subcategoria, "Definição de bullying", os dados indicaram que, embora as participantes conhecessem o fenômeno bullying, elas não mencionaram todas as principais características do fenômeno. Isso fica claro nas falas das participantes: "são maus tratos que a criança sofre de outras crianças" (Amanda), e "é a prática de diminuir o outro, não posso chamar de brincadeira, e sim uma ofensa, por causa de uma característica física, social. [...] Para mim é a prática de ofensa com o intuito de se sentir superior ao outro, diminuindo-o" (Fabiana). Isso indica que Amanda enfatiza os maus tratos que as crianças sofrem de outras crianças, enquanto Fabiana chama a atenção para a prática de diminuir o outro, ofendendo-o, para se sentir superior a ele.

Para Beatriz, o bullying é "uma forma de agressão, de intimidação, humilhação, uma maneira de diminuir o outro", enquanto, para Cecília, é "aquela situação em que o aluno se sente ofendido verbalmente ou até fisicamente, por algo que ele não pode transformar”, como características físicas ou mesmo roupas que ele não pode escolher. Percebe-se com isso que Beatriz compreende várias características referentes a situações de bullying, como a questão da agressão, da intimidação e da diminuição do alvo de bullying. Já Cecília, coloca a questão da ofensa com origem em algo da qual o alvo não pode mudar, o que não deixa de ser verdade, porém é uma definição que contém poucas características do fenômeno.

O fato de nem todas as participantes apresentarem as principais características da definição de bullying indica que a formação do professor é imprescindível para o enfrentamento do fenômeno (VENTURA; FANTE, 2011) quando se trabalha com alunos com deficiência. Os alunos com deficiência intelectual podem não ter os mesmos recursos para lidar com o bullying do que os demais estudantes e, em função disso, não conseguirem se defender e comunicarem aos adultos que estão sofrendo essa violência, o que pode dificultar a identificação dessas situações pelos professores (CASTRO, 2012). Diante disso, o professor precisa estar ainda mais atento e capacitado para identificar o fenômeno. Nesse sentido, as práticas pedagógicas são importantíssimas, desde a formação inicial dos professores, e essenciais para que sejam capazes de construir novos currículos aptos a abarcar a diversidade dos alunos (BORBA, 2020). Para que o professor possa realizar um bom trabalho, a infraestrutura escolar precisa ser aprimorada, pois, por melhor que seja a formação do professor, se não houver condições favoráveis para a execução de um trabalho inclusivo, o professor poderá ficar sobrecarregado e não conseguirá cumprir bem seu papel. (ALVES; XAVIER; PAULA, 2019; BORGES; DELLAZZANA-ZANON, 2019). 
Em relação à subcategoria "Ocorrência de bullying na escola", observou-se diferenças entre as participantes professoras-mães de pessoas com deficiência. Amanda afirma que o bullying é recorrente, "A gente faz o possível, conversa com a criança a respeito da situação, de você ter o respeito para com o próximo, [...], mas aqui as crianças vêm de um lado familiar muito penoso, a base familiar é complicada. (Amanda)". Já Fabiana, percebe pouco o bullying na sua atual realidade.

[...] com crianças pequenas, não vejo como uma prática muito recorrente, acho que ainda não é uma questão muito frequente neles, mas às vezes acontecem algumas discussões [...], então nós temos a preocupação de toda semana fazer uma leitura envolvendo o respeito às diferenças e a gente conversa bastante sobre isso. (Fabiana).

Quanto às professoras que não têm filhos com deficiência, Cecília mencionou que o bullying ocorre "[...] em situações em que o professor não está presente, então em situações de intervalo, quaisquer situações em que a escola está com uma atividade mais livre". Beatriz teve dificuldade em responder à questão. Isso pode ter ocorrido, pois se responderem que sabem em quais situações o fenômeno ocorre, as participantes podem ser questionadas sobre o motivo pelo qual não há intervenções em relação ao bullying. Pode-se citar como exemplos de aspectos que influenciam a qualidade do trabalho do professor em relação ao bullying: o grande número de alunos por professor, a falta de infraestrutura e o excesso de burocracia existentes na escola (ROCHA; FERNANDES, 2008). Deve-se considerar, também, como um dificultador da ação do professor, a tendência de o bullying ocorrer longe dos olhos dos adultos (CHAVES; SOUZA, 2018; TOGNETTA, 2012).

Em relação à subcategoria "Estratégias de ação das participantes em relação ao bullying vivenciado", as participantes mães de pessoas com deficiência disseram recorrer à empatia, ao diálogo e às reflexões. Amanda afirma que sua estratégia principal é a conversa:

[...] temos que conversar muito, apesar que as classes são muito numerosas, [...] de um lado começam brigas, a tirar sarro um do outro e quando você começa a acalmar os ânimos de um lado, vai para o outro. Muitas vezes você acaba 'perdendo' a sua aula, modificando para outras situações [...] é complicado para o professor sozinho. Quando há um professor de apoio, pedimos para ele olhar a classe enquanto vamos conversar fora. (Amanda).

Fabiana, por sua vez, enfatiza atividades planejadas para o trabalho com o fenômeno, mas também cita a importância da conversa: "[...] quando acontece alguma situação em sala de aula, nós retomamos aquilo que já foi conversado e eles reconhecem o erro, se desculpam". Esses exemplos indicam a preocupação das participantes em trabalhar a questão do bullying, usando estratégias planejadas para isso ou as próprias situações do cotidiano escolar. Assim, dependendo do que ocorrer em relação ao bullying, a atividade para tratar da temática é realizada, ainda que seja necessário alterar o plano de aula. Esses resultados corroboram os de um estudo anterior no qual as professoras generalistas tinham intervenções com caráter mais preventivo e as professoras especialistas com caráter mais pontual. (BORGES; DELLAZZANA-ZANON, 2019).

O mesmo foi observado com as duas participantes que não são mães de pessoas com deficiência. Beatriz (professora generalista) afirma trabalhar com regras desde o início do ano e com a questão das virtudes, principalmente com a empatia, sem deixar de realizar uma intervenção de modo pontual quando a situação relacionada ao bullying requer. Cecília (professora especialista) responde que "[...] quando acontece a ocorrência [de bullying] eu paro a aula e não permito que aconteça isso". Independentemente de haver estratégias de prevenção, a atitude pontual de Cecília é muito importante como estratégia antibullying, pois, para o alvo, ela é uma figura de autoridade, de alguém que percebe o seu problema e tem autoridade para interrompê-lo. 
As ações de combate ao bullying são amparadas pela Lei Antibullying, Lei no. 13.185/15 (BRASIL, 2015a), lei federal segundo a qual é dever de toda escola promover medidas de conscientização, prevenção, diagnóstico e combate ao bullying e ao cyberbullying. Essa lei é importante, pois promove políticas públicas de prevenção e de combate ao fenômeno como: capacitação docente e de equipes pedagógicas, implementação e disseminação de campanhas de educação, conscientização e informação.

\section{Educação inclusiva}

Em relação à subcategoria Definições de Escola Inclusiva (EI), as duas professoras-mães de crianças com deficiência respondem de formas diferentes. Amanda fez um histórico sobre a inclusão relatando sua experiência como professora e mãe, visto que sua filha ingressou na escola regular há algum tempo. Fabiana deu ênfase à escola inclusiva como professora, embora tenha mencionado sua experiência como mãe de uma criança com deficiência. Amanda afirmou que os professores e os colegas não lidaram bem com a sua filha com deficiência intelectual, por não compreenderem a sua deficiência e por relutarem em acreditar nela pelo fato dela não apresentar nenhum sinal externo da sua deficiência, além disso, ela reclamou da ausência de um plano de ensino desenvolvido especificamente para a filha na época.

As escolas que ela [sua filha] frequentou, [...] não tinham plano de aula preparado. A própria Secretaria de Educação não estava preparada para isso, deixando levar, a excluindo. [...] Eu sofri na pele junto com ela, que não tinha amigos, porque as pessoas não sabem lidar com um deficiente intelectual [...]. No início da inclusão ninguém sabia como fazer, ela tinha aula com estagiárias sem um plano correto para seguir, [...] pulando a alfabetização, inclusive ela não foi alfabetizada, saindo do nono ano sem ser alfabetizada. (Amanda).

Esse relato de Amanda indica que a escola inclusiva (EI) não conseguiu cumprir o seu papel. Sobre este aspecto da idade, segundo a LBI, os alunos com deficiência devem ser matriculados de acordo com sua faixa etária. Entretanto, também a LBI, em seu art. 28-V, determina, quando necessário, a adoção de medidas individualizadas para maximizar o desenvolvimento acadêmico e social dos estudantes com deficiência, favorecendo o acesso, a permanência, a participação e a aprendizagem em instituições de ensino (BRASIL, 2015b).

Após uma pequena crise de choro motivada pela pergunta sobre a EI, Fabiana a definiu como a escola que ela sonha para o seu filho, a que consegue ver o que a criança é capaz e não suas incapacidades. Fabiana afirma que até o ensino fundamental I, em que um único professor (generalista) fica a maior parte do tempo com a criança, ele ainda tenta fazer alguma coisa por ela, ainda que as condições sejam muito difíceis, diferente do ensino fundamental II, quando começa a ter um rodízio muito grande de professores (especialistas), que acabam desconhecendo a realidade de cada um dos alunos, dificultando o trabalho. Esse resultado indica que, na opinião desta participante, um professor generalista consegue fazer mais do que um professor especialista, pois passa mais tempo com o aluno, e, como consequência, o conhece melhor.

Fabiana relata sua vivência no ano anterior ao da entrevista com o ensino fundamental II, revelando o que pensa sobre EI nesse nível de ensino:

Como a minha experiência o ano passado foi do sexto ao nono, foi um ano bem difícil para mim, porque eu vi que ali é nula a inclusão, porque têm os estagiários e acham que isso é inclusão, pensando que, por ter o estagiário para acompanhar a criança, já estão cumprindo a lei [...] as meninas [estagiárias] têm muita boa vontade, [...] porém elas não têm todo aquele conhecimento do que fazer, e imagine uma estagiária no primeiro semestre de faculdade 
preparando aula de português, matemática, história, geografia, ciências, inglês, elas preparam tudo. O professor não dá um auxílio e foi isso que eu vi [...] não se dava nem ao trabalho de ver do que o aluno é capaz. [...] Mas, você acaba sendo vista como uma pessoa desagradável, querendo entrar num meio que não é seu, pois não sou formada naquela área para falar isso e os professores me disseram que realmente não davam conta de adaptar todo o conteúdo, mas se quem é formado e especialista não dá conta de adaptar o conteúdo, se coloque no lugar da estagiária que não é formada, não é especialista na área e tem que adaptar todas as disciplinas. (Fabiana).

A questão referente ao professor generalista e ao especialista também foi percebida em pesquisa realizada por Borges e Dellazzana-Zanon (2019), em que se constatou que a alta rotatividade de turmas que os professores especialistas possuem pode dificultar o aprofundamento no conhecimento da deficiência do(s) seu(s) aluno(s) e das relações que esse(s) estabelece(m) no ambiente escolar. Por outro lado, o professor generalista fica mais tempo com os alunos e, por isso, tem maior possibilidade de conhecê-los, aprofundar-se em suas potencialidades e dificuldades, conhecer suas relações interpessoais e as peculiaridades de sua deficiência (BORGES; DELLAZZANA-ZANON, 2019).

Talvez, por essa questão, Fabiana ainda retoma a questão afirmando:

No ensino fundamental I, percebo isso se dando de uma forma melhor, pois sinto uma certa preocupação das professoras em pelo menos pensar no que podem preparar para essas crianças, o que podem fazer para elas, para as estagiárias aplicarem. Mas, ainda assim, vejo que eles se tornam alunos das estagiárias, e não seria isso. As estagiárias estão ali para dar apoio, é direito deles, eu sei que um professor sozinho na sala de aula com trinta alunos é desumano, pois numa escola inclusiva, o primeiro passo seria diminuir a quantidade de alunos por sala. [...] Vejo a dificuldade que temos em sala de aula para desenvolver um trabalho de inclusão. Um auxiliar na sala ajuda, mas o professor é quem tem que preparar, saber onde ele está, onde quer chegar com ele. (Fabiana).

O relato de Fabiana evidencia a dificuldade do professor em atender a todos os alunos, considerando as classes numerosas com as quais a maioria trabalha, e chama atenção para a necessidade de um(a) auxiliar que trabalhe em conjunto com a professora, além de toda uma estrutura de EI.

Quanto às professoras que não são mães, Beatriz menciona que "EI é conseguir atender aos alunos de maneira integral, atendendo todas as necessidades que os alunos tenham, individuais, pois a EI não é só com o aluno com deficiência (ACD)". Cecília comenta que "a criança sem estar na escola, praticamente não existe, ela vai ter só interação familiar ou religiosa”. É fato que a concepção de escola inclusiva precisa ter novas perspectivas educacionais e aceitar a heterogeneidade como padrão (ANTUNES; RECH; ÁVILA, 2015; MANTOAN, 2015). Assim, para que a escola englobe as diferenças, são necessárias modificações estruturais, arquitetônicas e pedagógicas profundas e não somente a integração dos $\mathrm{ACD}$, que precisam se adaptar completamente à realidade da escola (ROPOLI et al., 2010).

Na subcategoria "Finalidades da educação inclusiva", as participantes Amanda e Fabiana novamente misturam seus papéis de professoras e mães de ACD. Amanda, que participou da implementação da escola inclusiva no município em que trabalha, falou sobre esse processo:

No início, ficávamos com receio. Quando começou a inclusão, todos os professores ficaram sem saber como trabalhar com essas crianças, [...] foi uma inclusão social [integração], para incluir essas crianças com a sociedade dita normal, para todos se conhecerem, uma adaptação. Essas crianças do início da inclusão foram cobaias, para que fosse visto tudo que deveria ser modificado. Há nove anos, era uma coisa, hoje já é outra, mas eles foram infelizmente cobaias, para se ver onde deveriam mudar, o que seria melhor. Inclusive os professores já estão vendo 
de uma outra forma, estão se preocupando mais em trabalhar com aquela criança, [...] porém tem que modificar muita coisa.

Hoje, preocupa-se mais com o aprendizado da criança. Os pais não vão ser eternos, eles deveriam fazer o possível para que essas crianças fossem alfabetizadas, o que é principal, para que ela possa pegar ônibus, ler. A alfabetização, além da socialização, é muito importante, independentemente da idade, por exemplo: ela [a sua filha] não pode mais frequentar porque a idade dela não favorece, mas depois essa pessoa sai da escola, sem saber ler e escrever. [...] eu gostaria que tanto ela como todos os outros tivessem uma situação assim: às tardes, iriam para determinado local, para aprender várias coisas, oficinas, como cuidar da casa, algo diferente para eles, para que entendam o que devem fazer, conviverem numa sociedade. (Amanda).

O relato de Amanda evidencia sua percepção de que, no início da inclusão escolar, havia uma preocupação maior com a socialização do aluno, e não com a sua aprendizagem.

Fabiana, por sua vez, afirma que a inclusão é positiva para todos os alunos: "todo mundo sai ganhando: a criança que foi incluída, as crianças que estão envolvidas, o profissional que está com ele. Você passa a ver as coisas de outra maneira e dar importância”. Em seguida, conta uma experiência que vivenciou, ao acompanhar um ACD, como professora auxiliar e que, segundo ela, não teve crédito por parte dos colegas, por ela ser mãe de uma criança com deficiência (CCD):

No ano passado, foi uma experiência forte para mim, pois a turma em que esse aluno estava [um ACD], estava com ele desde pequenininho, e eles eram bastante elogiados por serem tranquilos, uma turma tolerante, mais calma, em comparação com outras. Uma outra sala elogiada, também tinha um aluno de inclusão junto desde pequeno [...] mas as pessoas achavam que eu via assim por causa do meu filho e não davam tanta importância. (Fabiana).

Para Fabiana, muitos profissionais da educação ainda demonstram certa resistência quanto à EI e afirma que, embora ache que a inclusão ainda não ocorre como deveria, ela percebe que até o quinto ano as questões relativas à inclusão acontecem com um pouco mais de facilidade, pois "na maior parte do tempo, é um mesmo professor [generalista] que fica com aquele aluno, por isso, acredita ser impossível o professor não fazer nada por ele”. Ela percebe, entre os colegas generalistas, uma certa preocupação em preparar atividades para essas crianças, caso não consigam realizar as mesmas preparadas para a turma, mesmo que essas atividades sejam aplicadas por estagiárias, que dão apoio ao professor, uma vez que as turmas são bastante numerosas e muitas crianças precisam do professor.

Em relação ao que as participantes que não são mães pensam sobre a finalidade da educação inclusiva, Beatriz afirma que "a finalidade de que ele [o aluno] tem direito, necessita, e é uma obrigação social, essa é a maior finalidade”. Já Cecília, menciona que:

É a vida social da criança, ela tem o direito, já que se construiu essa instituição, que se deu uma obrigatoriedade na lei sobre a escola, de nenhuma forma ele deve estar separado, se vai ser numa classe separada ou não, porque a história vai mudando, pode ser que daqui dez anos, dê um 'clic' e alguém fale que o resultado é muito melhor separado, não sabemos. Hoje nós estamos tentando trabalhar com o que nos foi imposto, sala comum, mas a gente sabe que é muito difícil sem um professor auxiliando e quando manda é estagiário que tem menos conhecimento que nós, então de certa forma auxilia e não auxilia. É a vida social e tem que ser feita da melhor forma possível. (Cecília).

Essa fala de Cecília chama atenção para o aspecto histórico em relação à educação de alunos com deficiência. A integração surgiu na década de 1960 e, até os anos de 1990, foi o norteador do atendimento educacional às pessoas com deficiência (MANTOAN, 2015). Usava-se o termo 
integração para nomear a inserção dos alunos com deficiência nas escolas regulares, sistema em que alguns alunos conseguiam passar do sistema especial à escola regular, se adaptando a esta e passando por seleção prévia, mesmo que as turmas especiais ainda fossem separadas das regulares (MANTOAN, 2015). Nesse sentido, a inclusão, de fato, é uma mudança de perspectiva educacional, e não se refere somente aos alunos com deficiência, mas a todos os alunos, sem discriminação (MANTOAN, 2015). Para que a escola inclusiva seja possível, é necessário que o currículo escolar seja revisto e flexibilizado, para que as dificuldades de aprendizagem possam ser trabalhadas, e adequadas à comunidade na qual está inserida, além de garantir que todos os alunos possam participar plenamente de suas atividades (ANTUNES; RECH; ÁVILA, 2015).

A subcategoria "Educação inclusiva centrada no filho com deficiência" derivou apenas das professoras-mães, pelo fato de focar nos filhos com deficiência propriamente. Embora as professoras-mães tenham mencionado sobre suas vivências como mães nas subcategorias anteriores, optou-se por criar uma categoria específica para esse assunto, a fim de apresentar resultados que não foram mencionados anteriormente. Para Amanda, atualmente, algumas escolas estão mais preparadas para trabalhar com a inclusão do que outras e, paradoxalmente, percebe que, na cidade em que trabalha e na qual a filha estudou, as escolas de periferia acolhem melhor as crianças com deficiência do que as escolas com alunos com maior poder aquisitivo, mais preocupadas com os índices de aprendizagem nas provas oficiais. Um dos aspectos que mais se destaca em sua fala é a tristeza pelo fato da filha ter pulado etapas para ficar com os alunos da sua idade e não poder ter sido reprovada, o que fez com que ela chegasse no nono ano sem ser alfabetizada, tornando o ingresso no ensino médio inviável para ela. Nesse sentido, Amanda afirma com pesar que sua filha fez parte das "cobaias", para que modificações fossem feitas na escola inclusiva e expressa sua angústia quanto ao futuro da filha, uma vez que "os pais não são eternos". Amanda menciona que ainda pretende matricular sua filha no ensino médio oferecido pela Rede Estadual de Ensino, e não mais pela Rede Municipal, e salienta a necessidade de professor de apoio na sala de aula para que isso possa ocorrer.

Fabiana também se emocionou ao falar sobre a educação que espera para seu filho e mencionou que sonha com a escola ideal. Pode-se dizer que Fabiana, cujo filho com deficiência ainda está em fase escolar, espera poder poupar o filho de questões que Amanda mencionou não ter tido como evitar em relação à sua filha. Para Fabiana, o profissional de apoio é importante, mas o aluno com deficiência não deve ser delegado somente a ele. Ela sugere que o professor troque de papel com o profissional de apoio em algumas situações para se aproximar da CCD e tornar o trabalho mais efetivo. Segundo Fabiana, quando a inclusão acontece, todos saem ganhando, pois "passam a dar importância para a tolerância e há tranquilidade em relação a outras turmas [que não lidam com questões de inclusão]".

\section{Relação entre bullying e educação inclusiva}

Os resultados sobre a "Relação entre o bullying e a educação inclusiva" foram derivados de duas situações fictícias sobre bullying relacionadas a crianças com deficiência mental e física. As participantes foram solicitadas a responder como solucionariam tais situações caso elas fossem a professora da sala. Em relação à situação 1, que se referia a uma situação de bullying em relação a uma CCD intelectual, as duas professoras-mães mencionaram que parariam a aula para trabalharem a situação e tirariam a CCD da sala para conversar com a turma e explicariam a situação da criança. Amanda mencionou que sua filha passou por situações bem semelhantes na escola, que a filha era a "boba da corte" da classe e isso lhe doía muito como mãe. Fabiana buscaria fazer com que as crianças se colocassem no lugar do(a) personagem da história e pensassem como a mãe dele se sentiria ao saber que tratavam o filho daquela maneira. A forma como ambas comentaram 
a situação problema indica que não é possível pensar em solucioná-la sem pensar na sua condição de mães de CCD.

No que se refere às participantes que não são mães, Cecília mencionou que se "o professor visualizou e não fez nada, ele [o bullying] vai ocorrer [novamente] com certeza", o que deixa claro sua percepção de que o professor tem um papel fundamental no combate a esse tipo de violência. Cecília salientou que agiria da mesma forma caso a criança que sofresse bullying não tivesse deficiência e retomaria as regras predefinidas quanto aos limites em relação ao outro. Além disso, Cecília mencionou que envolveria os pais das demais crianças da turma, se elas estivessem rindo e/ou apoiando a situação, e também a direção da escola sempre que se fizesse necessário. Beatriz, por sua vez, chamou atenção para a questão do diálogo. Para ela, é necessário compreender a razão que levou o autor de bullying a realizar esta ação e é preciso ajudá-lo a se colocar no lugar do alvo de bullying para refletir sobre como se sentiria. Esses resultados indicam que Beatriz defende um trabalho voltado para o desenvolvimento da empatia entre os colegas, promovido com o auxílio do professor.

Na situação dois, o bullying ocorria com uma CCD física que, ao voltar para a sala depois do recreio, contava a situação vivida para a professora. As professoras-mães mencionaram soluções diferentes. Amanda teria uma resolução parecida com a da situação 1, de retirar a criança alvo de bullying da sala, enquanto conversaria com as demais e incentivaria o pedido de desculpas quando a criança voltasse para a classe. Já Fabiana, intensificaria o trabalho com o tema bullying, a partir da literatura infantil, com histórias que trouxessem o respeito às diferenças e colocaria os(as) autores(as) e o(a) alvo para conversarem.

No que se refere às participantes que não são mães, Beatriz defenderia o diálogo, assim como na situação anterior. Ela conversaria com o autor e com o alvo de bullying ao mesmo tempo. Com isso, a participante buscaria fazer com que o alvo de bullying pudesse expressar como se sentiu com a agressão na tentativa de que o autor de bullying compreendesse a gravidade da sua ação. Cecília, por sua vez, chamaria a família do autor de bullying para um trabalho em conjunto entre a escola e a família e, como uma última opção, puniria o autor de bullying, mandando-o embora cada vez que uma situação de bullying ocorresse. Segundo Cecília, "caso os pais não estejam comprometidos com este trabalho relacionado ao filho, pelo menos, vão ter que vir buscar o filho toda vez que o fenômeno for visto ou relatado, e isto vai afetá-los de alguma forma, para terem alguma ação".

\section{Considerações finais}

Este estudo teve como objetivo investigar as concepções de mães de filhos com deficiência, que são também professoras, sobre bullying relacionado à CCD no ensino fundamental I. Os resultados revelaram que as professoras-mães não aparentaram ter um conhecimento maior do que as demais participantes acerca do fenômeno bullying. Contudo, essas participantes manifestaram sentimento de tristeza e angústia, pois, ao responderem sobre as temáticas referentes à educação inclusiva, não deixaram de relatar suas próprias experiências como mães de PCD. Isso indica que o trabalho dessas professoras, que são também mães de PCD, é ainda mais difícil, já que é permeado pelos sentimentos concernentes ao seu papel de mãe, do qual é impossível se dissociar.

A ação das professoras quanto às situações hipotéticas de bullying mostrou que a despeito de serem ou não mães, elas têm claro a importância de seu papel no sentido de enfrentar o bullying e proteger seus alunos, independentemente do tipo de deficiência deles. Quanto à educação inclusiva, é consenso que, apesar dos avanços, muito ainda precisa ser feito no sentido de garantir a inclusão efetiva de estudantes com deficiência. Nesse contexto, o bullying é um desafio a mais, que precisa ser encarado quando se pensa na EI, pois, dependendo do tipo de deficiência, os alunos 
têm menos condições de reagir a essa forma de violência, o que aumenta a responsabilidade do professor de protegê-lo.

Este estudo é um primeiro passo no sentido de compreender melhor o que as professoras, que também são mães de PCD, pensam sobre o bullying em CCD. Sabe-se que as mães já são muito cobradas em relação ao cuidado de seus filhos e, quando seus filhos são PCD, a sobrecarga pode aumentar ainda mais, na medida em que precisam dar conta de muitas outras tarefas relacionadas ao cuidado e à educação de seus filhos. Sugere-se que outros estudos sejam realizados a fim de aprofundar o conhecimento sobre bullying e inclusão, que sirvam de base para a implementação de projetos de prevenção e intervenção de combate ao bullying e à exclusão, necessários tanto para as professoras dessas crianças como para as suas mães.

\section{Referências}

ALLEN, Kelly-Ann et al. Belonging: a review of conceptual issues, an integrative framework, and directions for future research. Australian Journal of Psychology, 2021. p. 1-16. Disponível em: https://www.tandfonline.com/doi/full/10.108 0/00049530.2021.1883409. Acesso em: 12 maio 2021.

ALVES, Maria Teresa Gonzaga; XAVIER, Flavia Pereira; PAULA, Túlio Silva. Modelo conceitual para avaliação da infraestrutura escolar no ensino fundamental. Revista Brasileira de Estudos Pedagógicos, v. 100, n. 255, p. 297-330, 2019. Disponível em: http://www.scielo.br/scielo.php?script=sci_arttext\&pid=S2176-66812019000200297\&lng=en\&nrm=iso. Acesso em: 12 maio 2021.

ANTUNES, Helenise Sangoi; RECH, Andréia Jaqueline Devalle; ÁVILA, Cínthia Cardona. Educação inclusiva e formação de professores: desafios e perspectivas a partir do Pacto Nacional pela Alfabetização na Idade Certa. Práxis Educativa (Brasil), v. 11, n. 1, p. 171-198, 2016. Disponível em: https://www.redalyc.org/articulo.oa?id=89442686009. Acesso em: 12 maio 2021.

BORBA, Bruna Barros. Os processos de aprendizagem e o Transtorno do Espectro do Autismo (TEA): do segundo ao terceiro ano do ensino fundamental. Cadernos do Aplicação, v. 33, n. 2, 2020. Disponível em: https://seer.ufrgs.br/ CadernosdoAplicacao/article/view/98853/60962. Acesso em: 12 maio 2021.

BORGES, Anna Karolina Santoro; DELLAZZANA-ZANON, Letícia Lovato. Bullying e inclusão no ensino fundamental I: ações de professores. Revista Educação Especial Santa Maria, v. 32, 2019. Disponível em: https://periodicos.ufsm.br/ educacaoespecial/article/view/31773. Acesso em: 12 maio 2021.

BOSSI, Tatiele Jacques; ARDANS-BONIFACINO, Héctor Omar. O bebê imaginado e a constituição das identidades materna, paterna e do bebê. Interação em psicologia, v. 19, n. 3, 2016. Disponível em: https://revistas.ufpr.br/psicologia/ article/view/34491. Acesso em: 12 maio 2021.

BOWLBY, John. Uma base segura: aplicações clínicas da teoria do apego. Porto Alegre: Artes Médicas, 1989.

BRASIL. Lei no 13.185, de 6 de novembro de 2015. Institui o Programa de Combate à Intimidação Sistemática (Bullying). Brasília, DF: Presidência da República, 2015a. Disponível em: http://www.planalto.gov.br/ccivil_03/_ato2015-2018/2015/ lei/l13185.htm. Acesso em: 12 maio 2021.

BRASIL. Lei no 13.146, de 6 de julho de 2015. Institui a Lei Brasileira de Inclusão da Pessoa com Deficiência (Estatuto da Pessoa com Deficiência). Brasília, DF: Presidência da República, 2015b. Disponível em: http://www.planalto.gov.br/ ccivil_03/_ato2015-2018/2015/lei/113146.htm. Acesso em: 12 maio 2021.

BREIVIK, Kyrre; OLWEUS, Dan. An item response theory analysis of the Olweus Bullying scale. Aggressive behavior, v. 41, n. 1, p. 1-13, 2015. Disponível em: https://onlinelibrary.wiley.com/doi/abs/10.1002/AB.21571. Acesso em: 17 jul. 2021.

BROOMHEAD, Karen. Acceptance or rejection? The social experiences of children with special educational needs and disabilities within a mainstream primary school. Education 3-13, v. 47, n. 8, p. 877-888, 2019. Disponível em: https:// www.tandfonline.com/doi/abs/10.1080/03004279.2018.1535610. Acesso em: 12 maio 2021.

CASTRO, Elani Cristina Vieira Magalhães. Concepções e práticas de professores frente a situações de bullying contra crianças com deficiência intelectual: um estudo exploratório. 2012. Dissertação (Mestrado em Educação) - Universidade 
Católica de Brasília, Brasília, 2012. Disponível em: https://bdtd.ucb.br:8443/jspui/handle/123456789/692. Acesso em: 12 maio 2021.

CASTRO, Elisa Kern; PICCININI, Cesar Augusto. A experiência de maternidade de mães de crianças com e sem doença crônica no segundo ano de vida. Estudos de psicologia (Natal), v. 9, n. 1, p. 89-99, 2004. Disponível em: http://www. scielo.br/scielo.php?script=sci_arttext\&pid=S1413-294X2004000100011\&lng=en\&nrm=iso. Acesso em: 12 maio 2021.

CHAVES, Denise Raissa Lobato; SOUZA, Mauricio Rodrigues de. Bullying e preconceito: a atualidade da barbárie. Revista Brasileira de Educação, Rio de Janeiro, v. 23, e230019, 2018. Disponível em: http://www.scielo.br/scielo.php?script=sci_arttext\&pid=S1413-24782018000100214\&lng=en\&nrm=iso. Acesso em: 14 maio 2021.

CHRISTMANN, Michele et al. Estresse Materno e necessidade de cuidado dos filhos com TEA na perspectiva das mães. Cadernos de Pós-graduação em Distúrbios do Desenvolvimento, v. 17, n. 2, p. 8-17, 2017. Disponível em: http://pepsic. bvsalud.org/scielo.php?script=sci_arttext\&pid=S1519-03072017000200002\&lng=pt\&nrm=iso. Acesso em: 13 maio 2021.

COSTA, Priscyla Gualberto de Lima; SANTOS, Ludmilla Ferreira; DOS SANTOS, Maryelle Ferreira. Estresse parental de crianças com Transtorno do Espectro Autista: uma revisão teórica. Journal of Specialist, v. 1, n. 4, 2019. Disponível em: http://www.journalofspecialist.com.br/jos/index.php/jos/article/view/118. Acesso em: 13 maio 2021.

DELLAZZANA-ZANON, Letícia Lovato; SATTLER, Marli Kath; FREITAS, Lia Beatriz de Lucca. A importância da inclusão da família na intervenção contra o bullying. Pensando famílias, p. 109-120, 2010.

LABORATÓRIO DE PSICOLOGIA E EPISTEMOLOGIA GENÉTICA [LAPEGE/UFRGS]. Questionário sobre formação e trabalho das educadoras (Instrumento não publicado). Instituto de Psicologia, Universidade Federal do Rio Grande do Sul, RS, 2010a.

LABORATÓRIO DE PSICOLOGIA E EPISTEMOLOGIA GENÉTICA [LAPEGE/UFRGS]. Roteiro de entrevista sobre autonomia (Instrumento não publicado). Instituto de Psicologia, Universidade Federal do Rio Grande do Sul, RS, $2010 \mathrm{~b}$.

LAVILLE, Christian; DIONNE, Jean. A construção do saber: Manual de metodologia da pesquisa em Ciências Humanas. Porto Alegre: Editora Artes Médicas Sul Ltda, 1999.

LOPES NETO, Aramis A. Bullying: comportamento agressivo entre estudantes. Jornal de Pediatria, v. 81, n. 5, p. 164 172, 2005. Disponível em: https://www.scielo.br/pdf/jped/v81n5s0/v81n5Sa06.pdf. Acesso em: 12 maio 2021.

MAMAS, Christoforos et al. Friendship and support networks among students with disabilities in middle school. International Journal of Educational Research, v. 103, p. 101608, 2020. Disponível em: https://www.sciencedirect.com/ science/article/abs/pii/S0883035520303414. Acesso em: 12 maio 2021.

MANTOAN, Maria Teresa Eglér. Inclusão Escolar: O Que É? Por Quê? Como Fazer?. São Paulo: Moderna, 2015.

MOONEY, Sibhan; SMITH, Peter. Bullying and the child who stammers. British Journal of Special Education, v. 22, n. 1, p. 24-27, 1995. Disponível em: https://nasenjournals.onlinelibrary.wiley.com/doi/abs/10.1111/j.1467-8578.1995. tb00907.x. Acesso em: 12 maio 2021.

OLIVEIRA, Isaura Gisele; POLETTO, Michele. Vivências emocionais de mães e pais de filhos com deficiência. Revista da SPAGESP, v. 16, n. 2, p. 102-119, 2015. Disponível em: http://pepsic.bvsalud.org/scielo.php?script=sci_arttext\&pi$\mathrm{d}=$ S1677-29702015000200009\&lng=pt\&nrm=iso\&tlng=pt. Acesso em: 12 maio 2021.

PALACIOS, Jesús. Mudança e desenvolvimento durante a idade adulta e a velhice. In: COLL, César; PALACIOS, Jesús; MARCHESI, Álvaro. Desenvolvimento psicológico e educação: psicologia evolutiva. Porto Alegre: Artmed, 2004. p. 371-388.

PANIAGUA, Gema. A família de crianças com necessidades educativas especiais. In: SOUZA, Angela Maria Costa (ed.). A criança especial: temas médicos, educativos e sociais. São Paulo: Roca, 2003. p. 330-346.

PEGORARO, Camila; SMEHA, Luciane Najar. A experiência da maternidade na velhice: implicações do cuidado ao filho com deficiência intelectual. Barbarói, n. 39, p. 235-254, 2013. Disponível em: http://pepsic.bvsalud.org/scielo. php?script=sci_arttext\&pid=S0104-65782013000200011. Acesso em: 12 maio 2021.

OLIVEIRA, Wanderlei Abadio et al. Modos de explicar o bullying: análise dimensional das concepções de adolescentes. Ciência \& Saúde Coletiva, v. 23, p. 751-761, 2018. Disponível em: https://www.scielosp.org/article/csc/2018.v23n3/751761/. Acesso em: 12 maio 2021.

ROCHA, Vera Maria; FERNANDES, Marcos Henrique. Qualidade de vida de professores do ensino fundamental: uma perspectiva para a promoção da saúde do trabalhador. Jornal Brasileiro de Psiquiatria, v. 57, n. 1, p. 23-27, 2008. Disponível em: https://doi.org/10.1590/S0047-20852008000100005. Acesso em: 12 maio 2021. 
ROPOLI, Edilene Aparecida et al. A educação especial na perspectiva da inclusão escolar. A escola comum inclusiva. Brasília, DF: Ministério da Educação: Secretaria de Educação Especial, 2010. Disponível em: http://portal.mec.gov.br/ index.php?option=com_docman\&view=download\&alias=7103-fasciculo-1-pdf\&Itemid=30192. Acesso em: 12 maio 2021.

ROSE, Chad A.; MONDA-AMAYA, Lisa E.; ESPELAGE, Dorothy L. Bullying perpetration and victimization in special education: A review of the literature. Remedial and Special Education, v. 32, n. 2, p. 114-130, 2011. Disponível em: https://journals.sagepub.com/doi/10.1177/0741932510361247. Acesso em: 12 maio 2021.

SAMEROFF, Arnold. A unified theory of development: A dialectic integration of nature and nurture. Child development, v. 81, n. 1, p. 6-22, 2010. Disponível em: https://srcd.onlinelibrary.wiley.com/doi/abs/10.1111/j.1467-8624.2009.01378.x. Acesso em: 14 jul. 2021.

SANTOS, Saionara Figueiredo; MOLON, Susana Inês. Preconceito e bullying na constituição de uma professora de libras: experiências de uma surda. Revista Educação Especial, v. 29, n. 56, p. 723-735, 2016. Disponível em: https:// periodicos.ufsm.br/educacaoespecial/article/view/20179. Acesso em: 12 maio 2021.

SILVA, Stéffanie Mayara dos Santos; MARTINS, Bárbara Amaral. Escola regular ou escola especial? A escolha na visão de familiares de alunos com Síndrome de Down. In: PÉREZ, José Carlos Núñez et al. (comps.). Perspectiva psicológica y educativa de las Necesidades Educativas Especiales. Oviedo: Scinfoper, 2017. p. 47-54. Disponível em: https://formacionasunivep.com/files/publicaciones/LIBRO\%20perspectivas-psicologicas.pdf\#page=48 Acesso em: 12 maio 2021.

SINGH, Ritu; CHOPRA, Geeta. 'I am like everyone else...'Voices of Children with Disabilities in school settings: A Literature Review. Integrated Journal of Social Sciences, v. 6, n. 2, p. 35-38, 2019. Disponível em: http://pubs.iscience. in/journal/index.php/ijss/article/view/879. Acesso em: 12 maio 2021.

SMEHA, Luciane Najar; OLIVEIRA, Véra Lúcia Pacheco. Inclusão escolar: a perspectiva das mães de alunos com Síndrome de Down. Revista Educação Especial, v. 27, n. 49, p. 403-415, 2014. Disponível em: https://periodicos.ufsm. br/educacaoespecial/article/view/5908. Acesso em: 12 maio 2021.

SUDERMANN, Marlies; JAFFE, Peter G.; SCHIECK, Elaine. ASAP: A school-based anti-violence program. London: London Family Court Clinic, 1996.

TOGNETTA, Luciene Regina Paulin. Vencer o bullying escolar: o desafio de quem se responsabiliza por educar moralmente. In: TOGNETTA, Luciene Regina Paulina; VINHA, Telma Pileggi. É possível superar a violência na escola? Construindo caminhos pela formação moral. São Paulo: Editora do Brasil, 2012.

UNNEVER, James Douglas; CORNELL, Dewey Gene. The culture of bullying in middle school. Journal of School Violence, v. 2, n. 2, p. 5-27, 2003. Disponível em: https://www.tandfonline.com/doi/abs/10.1300/J202v02n02_02. Acesso em: 12 maio 2021.

VENTURA, Alexandre; FANTE, Cleo. Bullying: intimidação no ambiente escolar e virtual. Belo Horizonte: Conexa, 2011.

Data de submissão: 15/05/2021

Data de aceite: 03/08/2021 